\title{
Deliberative indispensability and epistemic justification *
}

\author{
Tristram McPherson \\ Virginia Tech \\ tristram@vt.edu \\ David Plunkett \\ Dartmouth \\ david.plunkett@dartmouth.edu \\ Ms. for submission to Oxford Studies in Metaethics \\ January 3, 2014
}

\section{Introduction}

According to one influential view in metaethics (e.g. Harman 1977, Boyd 1988), we are justified in believing in ethical facts just in case they (or their reduction base) feature in our best explanations of scientifically respectable phenomena. This naturalistic criterion, however, can seem to miss a crucial point. Many of us care about the existence of ethical facts not because of scientific-explanatory roles that they may play, but rather because we seemingly need such facts to make adequate sense of our practical lives. This suggests a Tempting Idea: that the (putative) indispensability of belief in ethical facts for our practical projects - including, for example, the project of deliberating about what to do - can justify our belief in such facts. Some version of this idea has attracted a range of philosophers, including Christine Korsgaard (1996), Ronald Dworkin (2011), and T. M. Scanlon (2014).

Any philosopher hoping to develop the Tempting Idea needs to answer two questions. First: which beliefs are relevantly indispensable? And second: what is the significance of this indispensability? David Enoch has recently spelled out a powerful and novel variant of the Tempting Idea, which he develops primarily in "An Outline of an

\footnotetext{
* Thanks to Joshua Schechter and especially David Enoch for extensive and invaluable discussion. Thanks also to Selim Berker, David Braddon-Mitchell, Sarah Buss, Brad Cokelet, Stephen Darwall, Billy Dunaway, Kenny Easwaran, Allan Gibbard, Nadeem Hussain, John Ku, Dustin Locke, Kate Manne, Howard Nye, Peter Railton, Sharon Street, Mike Titelbaum, and to audiences at the 2013 Madison Metaethics Workshop, and at David Plunkett's presentation at the Author Meets Critics session for Taking Morality Seriously at the 2012 Eastern APA.
} 
Argument for Robust Metanormative Realism” (2007) and Chapter Three of his Taking Morality Seriously (2011b). Enoch's account offers ambitious answers to each of these questions.

In response to the first question, Enoch argues for the indispensability of belief in what he calls Robust Realism about ethical facts. ${ }^{1}$ According to Robust Realism, ethical facts are ungrounded, irreducibly normative, and psychology-independent. Further, Enoch claims that Robust Realism is incompatible with a quietist or quasi-realist interpretation of these metaphysical claims. Enoch argues that such belief is indispensable to the project of practical deliberation: the project that we engage in when we seek to choose what to do (2011b, 70-73). This idea is intensely controversial and well worth examining. However, in this paper we set it aside, in order to focus on Enoch's answer to the second question.

In response to the second question, Enoch argues that deliberative indispensability is significant because such indispensability can epistemically justify belief. More precisely, Enoch defends:

Indispensabilism If a belief-forming method is indispensable to the project of practical deliberation, then that method is a source of basic epistemic justification

For someone hoping to develop the Tempting Idea into a response to the naturalistic epistemic criterion mentioned at the beginning of this paper, Indispensabilism has three striking virtues. First, it claims to underwrite epistemic justification. If defensible, it thus constitutes a direct rebuttal to the naturalistic criterion. Absent this claim, a defense of the Tempting Idea threatens to suggest that our capacity for practical deliberation dooms us either causally or rationally - to epistemic irrationality. Second, Indispensabilism promises to ameliorate a standard worry about metaethical views that violate the naturalistic criterion: that they are implausibly forced to posit a capacity to directly perceive non-

\footnotetext{
${ }^{1}$ Two clarificatory notes. First, we treat facts as the standard metaphysical relata throughout, while Enoch typically talks of truths. We take this change to be unobjectionable given Enoch's commitments, a point that he himself emphasizes (2011, 5). Second, and more importantly, we talk of ethical facts, where Enoch tends to talk of normative facts. We mean 'ethical' here broadly, to refer to the normative (or evaluative) facts that govern our practical lives. We insist on the change because epistemic facts are also normative, and because the contrast between ethical and epistemic normativity is central to our project here.
} 
natural ethical facts. A proponent of Indispensabilism can argue that our justification for belief in such facts is explained by the deliberative indispensability of such belief, rather than by a mythical perceptual capacity. A third virtue of Indispensabilism is its neutrality concerning the nature and grounds of ethical facts. One might try to defend the Tempting Idea in part by arguing that facts about indispensability explain the fundamental ethical facts. By contrast with this approach, if Indispensabilism could be defended, it might be adapted to permit proponents of a variety of metaethical views to vindicate the Tempting Idea.

For these reasons, we take Indispensabilism to be an important and well-motivated thesis. However, in this paper, we argue that Indispensabilism should be rejected. The core reason is this: Indispensabilism conflicts with part of what is distinctive of epistemic justification.

The distinctiveness of epistemic justification can be suggested by the following thought experiment. Suppose that Hallie has taken a powerful drug that permits her immediate voluntary control over her beliefs. ${ }^{2}$ That is, with a little effort, she can simply intentionally make herself believe a proposition she currently does not believe. Suppose further that a tone-deaf evil demon approaches her. The demon demonstrates his singing incompetence, and then issues a credible threat: unless Hallie now believes that the demon sounds exactly like Ray Charles, he will brutally torture every sentient being that exists. Thanks to the drug, Hallie can form the belief that the demon sings like Ray Charles. And she clearly has decisive ethical justification to do so. But Hallie has no epistemic justification for this belief. She will be epistemically irrational if she does what she ethically ought to do. The case of Hallie dramatizes the familiar point that ethical and epistemic normativity appear to be very different things, by showing that one can have overwhelming ethical justification for a belief, while lacking any epistemic justification for it. ${ }^{3}$

\footnotetext{
${ }^{2}$ For (in our view exaggerated) doubts about the coherence of such a possibility, see Williams 1972.

${ }^{3}$ There might be other ways of drawing the distinction between Hallie's different reasons that would work for our argumentative purposes in this paper. Our point is that however one draws this distinction, the case of Hallie brings out an intuitive and important contrast between two different sets of norms that an agent can be subject to. We are characterizing one set of these norms as the norms of genuine epistemic justification, and we submit that it is deeply intuitive that only one set of these norms can plausibly be understood this way.
} 
This stark contrast permits us to pose two crucial questions about Indispensabilism: is the fact that something is deliberatively indispensable the right sort of thing to underwrite epistemic justification? Or can that fact at best underwrite only ethical reasons for belief? We argue that deliberative indispensability is inconsistent with part of what is distinctive of epistemic justification, and hence that Indispensabilism must be rejected.

Our paper proceeds as follows. We start $\S 1$ by laying out our exemplary stalking horse: Enoch's case for Indispensabilism $(\S 1)$. We then argue that Enoch's case fails because it elides a distinctive feature of genuinely epistemic justification, a feature that we dub Truth-Directedness (§2). Briefly, according to Truth-Directedness, the norms of epistemic justification have the content they do because of some positive connection to the truth of the beliefs these norms govern. (We give a more precise characterization of this thesis in what follows). Because Enoch's account fails to respect a crucial part of what is distinctive about epistemic justification, it thereby fails as a defense of Indispensabilism (which, recall, is a thesis about epistemic justification). Enoch's specific proposal, however, is just one possible attempt to defend Indispensabilism. We go on to argue that our objection generalizes to a range of salient alternatives to Enoch's way of defending Indispensabilism, that are based on leading general approaches in contemporary epistemology. We argue that this generalization reveals a general tension between TruthDirectedness and Indispensabilism (and not just Enoch's particular defense of it). We thus conclude that deliberative indispensability does not epistemically justify belief (§3). Although our main argument in this paper is directed at Indispensabilism, part of our goal here is to get clearer on what it would take to defend the Tempting Idea, and to assess the prospects of doing so. We thus examine three ways of attempting to salvage the initial Tempting Idea, in the face of our argument. We briefly argue that each of these attempts faces significant costs. In light of this, we suggest that pessimism is warranted about the Tempting Idea itself (§4). We conclude the paper with some brief reflections on the broader metaethical significance of our arguments $(\S 5)$.

\section{Enoch's defense of Indispensabilism}


In this section and the next, we aim to illustrate the promise and perils of Indispensabilism by exploring its powerful recent defense by David Enoch. In this section, we first explain the role of that defense in Enoch's case for his Robust Realism about ethical facts. This illuminates part of the potential metaethical significance of Indispensabilism. We then lay out the details of Enoch's case for Indispensabilism, which puts us in a position to evaluate it in the following section.

\subsection{From deliberative indispensability to Robust Realism}

To understand any indispensability argument, one must understand the notion of indispensability being deployed. We thus begin by unpacking two technical notions that Enoch introduces: an intrinsically indispensable project, and something's being instrumentally indispensable to such a project. We then introduce the outline of Enoch's ambitious deliberative indispensability argument for Robust Realism about ethical facts.

On Enoch's account, a project is intrinsically indispensable if it is "rationally nonoptional", such that disengaging from it "is not a rationally acceptable option" $(2011,70) .{ }^{4}$ This entails that one is rationally criticizeable if one does disengage from such a project. It is worth emphasizing that this account is explicitly normative. A project thus does not count as intrinsically indispensable in Enoch's sense simply because one is stuck with engaging in it (in the non-normative sense of "stuck with"). ${ }^{5}$

There can be necessary conditions for pursuing such a project. According to Enoch, for something to be instrumentally indispensable to a project is for its elimination to undermine or attenuate the reasons that we had for engaging in that project in the first

\footnotetext{
${ }^{4}$ While some philosophers (e.g. Broome 1999 and Kolodny 2005) use "rationality" to talk about distinctively structural normativity, Enoch uses "rationality" here as a way to talk about substantive ethical facts.

${ }^{5}$ On this point, Enoch 2011b differs from his 2007 presentation of his indispensability argument. This change makes Enoch's metaethical views more consistent: as he himself notes, the earlier version of his argument faces his own well-known "schmagency" challenge to attempts to explain authoritative normativity in terms of necessary facts about agency (Enoch 2006). The change also allows Enoch to avoid intuitive worries that afflict his earlier argument. For example, we can imagine possible creatures who are doomed to engage in worthless projects - perhaps because they were designed to be doomed in this way. It is especially hard to see why serving such a project could epistemically justify otherwise unsupported beliefs. For these reasons, we take Enoch's explicitly normative gloss on intrinsic indispensability in his $2011 \mathrm{~b}$ to be a significant improvement on the original 2007 version.
} 
place. Crucially, Enoch wants to distinguish such instrumentally indispensable features from mere "enabling conditions" for a project. For example, take the relationship between getting adequate sleep and the project of engaging in scientific enquiry. Enoch claims that while getting enough sleep might be an enabling condition for this project, it is not instrumentally indispensable to this project, in the sense of "instrumentally indispensable" that he has in mind $(2011,68)$.

With these clarifications in hand, we can now present a schematic form of Enoch's overall indispensability argument: ${ }^{6}$

1. If treating a belief-forming method as a source of basic epistemic justification is instrumentally indispensable to an intrinsically indispensable project, then that method is a source of basic epistemic justification (2011, 60-64).

2. The project of deliberation is intrinsically indispensable $(2011,70-73)$.

3. Treating our intuitive commitments in deliberation as a source of basic epistemic justification is instrumentally indispensable to the deliberative project (cf. 2011, 67-69).

4. Therefore, our intuitive commitments in deliberation are a source of basic epistemic justification (from premises 1-3).

5. In deliberation, we are intuitively committed to the existence of ethical facts, as they are conceived of by the Robust Realist (2011, 71-79).

6. Therefore, (because sources of basic epistemic justification provide defeasible epistemic justification) we have defeasible epistemic justification for believing in the existence of robustly real ethical facts. (from premises 4-5)

Premises (1) and (2) of this argument entail (a variant of) Indispensabilism. The remainder of the argument shows that, together with the further claims about deliberation in premises (3) and (5), Indispensabilism can supports an ambitious metaethical view: namely, Robust Realism about ethical facts.

\footnotetext{
${ }^{6}$ Enoch provides a simpler schematic summary of his argument $(2011,83)$. However, because that reconstruction elides detail in his argument that is crucial to our discussion here, we have provided our own, slightly more complex summary here.
} 
This argument illustrates the potential metaethical significance of Indispensabilism, and also why it is such a powerful way of developing the Tempting Idea that we introduced at the start of this paper. Enoch's argument appears to offer a clear and principled account of how epistemically justified belief in non-natural ethical facts is possible, and, moreover, does so in a way that also constitutes a positive argument on behalf of Robust Realism in metaethics.

We have significant worries about premises (2), (3), and (5) of the argument. ${ }^{7}$ However, the metaethical bite of Indispensabilism extends beyond Enoch's own defense of this thesis. This is because the basic Indispensabilist idea could potentially be combined with a variety of auxilliary commitments (in lieu of premises (2-5)), to epistemically justify various commitments in or about ethics. The epistemic heart of Enoch's argument that achieves these results is premise (1). In the next subsection, we thus explore Enoch's case for this premise in detail.

\subsection{Enoch's strategy for vindicating Indispensabilism}

Enoch's defense of Indispensabilism presupposes a foundationalist picture of the structure of epistemic justification. On this picture, certain belief-forming methods are epistemically derivative while others are epistemically basic. Consider an example of an epistemically derivative method: someone might be justified in using the results of a DNA test as evidence of paternity, but only because she has prior evidence of the reliability of the test. By contrast, consider belief-forming methods such as reliance on sense-perception and memory, inference to the best explanation, and inference rules like modus ponens. Enoch claims that these methods are epistemically basic: using these methods can produce defeasibly epistemically justified belief, even when we lack independent epistemic justification for

\footnotetext{
${ }^{7}$ Premise (3) could reasonably be challenged by purveyors of anti-intuitionist approaches to moral epistemology. With premises (2) and (5), Enoch faces a version of a dilemma he himself has pressed against the constitutivist: the more you build into a conception of deliberation, the less plausible it is that doing that is rationally non-optional $(2011 \mathrm{~b}, 71-2)$. We find it especially doubtful that belief in an explanatorily robust form of naturalistic realism (whatever its other vices) would not suffice to vindicate deliberation. For a challenge to the assumption that belief in any sort of substantive or authoritative normativity is indispensable to deliberation, see (Husi 2013, §4).
} 
using them (Enoch 2011b, 58; cf. Enoch and Schechter 2008). For uniformity, we will call these methods sources of basic epistemic justification.

Enoch argues that philosophers who endorse the foundationalist picture face the burden of explaining the facts in virtue of which only some belief forming methods are basic justifiers (Enoch 2011, 59ff, Enoch and Schechter 2008, 547). What, we might demand, explains the contrast between reliance on memory and reliance on DNA testing? Note that this is not a request for an epistemic justification for treating certain sources as basic. Rather, the question is: what explains why these sources have that very status of being epistemically basic?

Enoch calls the sort of explanation he is after here a "vindication". Enoch's own glosses on this term are not totally clear in the details. We will understand a vindication as an explanation of the distinctive epistemic status of the methods that are basic sources of justification, where this explanation supports, rather than debunks (or reforms away), the intuitive normative significance of these sources (cf. 2011b, 60). One might be able to provide a vindication in this sense by using one of a variety of different types of philosophical explanation. ${ }^{8}$ We think that Enoch's own approach to offering a vindication is best understood as a grounding account: a metaphysical account that explains the facts in virtue of which certain sources provide basic epistemic justification. ${ }^{9}$ We join Enoch in taking the demand for a vindication of the sources of basic epistemic justification to be forceful (modulo the controversial assumption of the truth of foundationalism). And we are happy to grant for the sake of argument that such a vindication should take the form of a grounding account. Our concern in this section is with the specific grounding account that Enoch proposes.

Because Enoch calls his vindicating account a "pragmatic" one, we will appropriate this handy (if slightly misleading) label to refer to his account. This account can be stated as follows:

\footnotetext{
${ }^{8}$ Consider two alternatives. First, one might propose a vindication of the sources of basic epistemic justification by providing an ontological reduction of the source of basic epistemic justification relation. Second, a proponent of ambitious conceptual analyses (à la Jackson 1998) might propose a vindication via an analysis of the concept BASIC SOURCE OF JUSTIFICATION that illuminated its extension.

${ }^{9}$ For a helpful overview of grounding in contemporary metaphysics, see Trogdon 2013.
} 
Pragmatic Something is a source of basic epistemic justification in virtue of the fact that treating it as such a basic source is instrumentally indispensable to an intrinsically indispensable project. ${ }^{10}$

Pragmatic trivially entails premise (1) of Enoch's argument. And it is thus the crucial step in his case for Indispensabilism (we are granting him the other element of that case: the assumption that deliberation is an intrinsically indispensable project). En route to assessing Pragmatic's plausibility as a vindicating account for the sources of basic epistemic justification, we sketch three virtues of this thesis.

Pragmatic's first virtue is that it appears to offer a credible explanation of the substantive normativity of the basic epistemic justification facts. What do we mean by this? Contrast epistemic norms with the norms of chess, or fashion. Indifference to the "epistemic evaluation game" seems like an objective flaw, in a way that indifference to chess or the norms of fashion does not: the epistemic norms appear to have normative substance in a way these other norms do not. ${ }^{11}$ As we have seen, Enoch's conception of indispensability appeals to ethical facts, which are themselves substantively normative. It thus entails that basic epistemic justification facts will be grounded partly in substantively normative facts. Because grounding can arguably transmit normativity, being grounded in substantively normative facts seems like an excellent way to explain the substantive normativity of the epistemic justification facts.

Second, Enoch suggests that Pragmatic is plausible in part because it is capable of explaining the epistemic status of a plausible range of the sources of basic epistemic justification. Enoch takes inference to the best explanation (IBE) as his leading illustration.

On Enoch's account, IBE is a source of basic epistemic justification because (i) the project of understanding and explaining the world around us is rationally non-optional, and (ii) deploying IBE is instrumentally indispensable for creatures like us pursuing this project (2011, 60-61).

\footnotetext{
${ }^{10}$ Enoch's clearest official statement of his thesis $(2011 \mathrm{~b}, 63)$ provides a mere sufficiency condition for being a source of basic epistemic justification. But Enoch clearly intends the thesis to be explanatory, and our formulation reflects that fact.

${ }^{11}$ See McPherson 2011, Sec. 4 for a brief exploration of this contrast, in terms of "formal" vs. "robust" normativity.
} 
Enoch's focus on IBE has a further, dialectical payoff. The naturalistic criterion for justifying commitment to ethical facts that we introduced at the beginning of this paper appeals crucially to IBE. And this criterion seriously threatens Enoch's Robust Realism, since, on this view, the fundamental ethical facts are irreducible and do not explain anything non-normative. It also threatens all arguments from deliberative indispensability, since deliberative indispensability does not entail explanatory indispensability.

If we suppose that Enoch is right that Pragmatic is the most plausible vindication for the epistemic status of IBE, however, the threat posed by the naturalistic criterion is neutralized. This is because (as Enoch argues) Pragmatic can vindicate other sources of basic epistemic justification besides IBE. Further, deliberative indispensability arguments are no longer threatened, because deliberative indispensability is claimed to explain the epistemic status of IBE itself. In the next section, we will argue that despite these promising features, Enoch's vindicating account is unsuccessful.

\section{Epistemic justification and truth}

This section sets out our case against Pragmatic - Enoch's vindicating account of the sources of basic epistemic justification. We begin by articulating and defending a partial characterization of what is distinctive of epistemic justification: that it is truth-directed (§2.1). We then introduce three intuitive counterexamples to Pragmatic, and argue that the force of these counterexamples is well-diagnosed in terms of the truth-directedness of epistemic justification $(\S 2.2)$. We argue that our theory of the truth-directed nature of epistemic justification, coupled with these counter-examples, gives us strong reason to reject Pragmatic (\$2.3).

A vindicating account of a phenomenon is supposed to explain and uphold our intuitive commitments with respect to that phenomenon, rather than debunking or substantially reforming them. A vindicating account of the sources of basic epistemic justification should thus accomplish at least the three following goals. First, it should explain (or at least be compatible with) the most plausible theses about which sources of epistemic justification are basic. Second, it should explain (or at least be compatible with) the apparent normative substantiveness of the norms of epistemic justification. Third, it 
should explain (or at least be compatible with) our sense of what is distinctive of the norms of epistemic justification.

In the previous subsection, we saw that Enoch makes a prima facie case that Pragmatic meets the first desideratum, by arguing that Pragmatic can explain the status of belief-forming methods like IBE. We also saw that because Pragmatic grounds facts about the sources of basic epistemic justification partly in ethical facts, there is a good case to be made that it meets the second desideratum.

The third desideratum demands that a vindicating account of the sources of basic epistemic justification explain (or at least be compatible with) what is distinctive of epistemic justification. There is little in Enoch's work that explicitly addresses the third desideratum. Further, recall the case of Hallie that we set out in the Introduction. As this case shows, epistemic and ethical justification look like radically different creatures. This licenses initial suspicion that an account like Pragmatic, which seeks to ground the sources of basic epistemic justification partly in ethical norms, will struggle to satisfy this desideratum. We argue that this initial suspicion is warranted: Pragmatic should be rejected precisely because it is incompatible with a central distinctive feature of epistemic justification. This is a feature that we call Truth-Directedness.

\subsection{Truth-Directedness}

Recall the case of Hallie and the demon. The demon will torture every sentient being unless Hallie now believes that the demon's singing voice sounds exactly like Ray Charles's. As we emphasized, this fact fails to provide basic epistemic justification for Hallie's believing that the demon sounds exactly like Ray Charles's. A compelling explanation of this failure is that this fact about the consequences of Hallie's belief is wholly unconnected to the truth of the proposition that the demon's singing voice sounds like Ray Charles. If this diagnosis is right, it suggests that any adequate explanation of the sources of basic epistemic justification will need to appeal in a central way to some link between those sources and true belief.

We endorse a specific, although highly schematic, account of this link, which we call: 
Truth-Directedness the sources of basic epistemic justification have the content that they do (in part) because of some positive connection between those sources and the truth of the beliefs that they govern

We now clarify three elements of this thesis: the appeal to truth, to explanation ("because"), and to positive connection.

First, in adverting to truth, we do not intend to commit ourselves to anything incompatible with deflationary accounts of truth. The thesis could be stated (more clumsily) in terms of a positive connection between a) beliefs that $\mathrm{P}$ and $\mathrm{b}$ ) $\mathrm{P}$.

Second, the thesis asserts that the connection between the truth and the sources of basic epistemic justification must be explanatory. The thesis is thus fundamentally a constraint on theories that purport to explain why something is a source of basic epistemic justification. According to Truth-Directedness, all such theories must advert to some positive connection to truth as a criterion. Consider an example where this connection fails: a crude epistemic divine command theory. This theory states that for a source to be epistemically basic is for God to demand that you treat it as basic. This theory violates the explanatory requirement of Truth-Directedness. Note that even if God in fact ensured that the sources he commanded you to rely on are reliable, the link to truth thereby secured is not part of this theory's account of what explains why something is a source of basic epistemic justification. We think that the fact that this theory violates Truth-Directedness is one sufficient explanation of why this theory fails as an account of epistemic justification.

Crucially, Truth-Directedness is a demand on the theory that explains epistemic basicness, not on the basic sources themselves. Truth-Directedness thus does not require that a source of basic epistemic justification must "have truth as a goal". For example, conceptual competence with the concept AND does not obviously involve having truth as a goal, any more than competence with the concept TONK does. ${ }^{12}$ This is compatible with a theory of the sources of basic epistemic justification saying (for example) that our

\footnotetext{
${ }^{12}$ Here and below, we follow one standard convention and designate concepts with smallcaps.
} 
competence with the former, and not the latter, is a source of basic epistemic justification, in part because the first concept is truth-preserving while the second is not. ${ }^{13}$

Third, Truth-Directedness requires some positive connection between the sources of basic epistemic justification and truth. We intend this thesis in a very ecumenical spirit. Thus, some epistemologists might precisify the positive connection in modal terms: for example in terms of reliability or safety. Others might flesh it out in terms of the constitutive goals of epistemic agents, or in terms of conditions for responsible pursuit of the truth. Still others might appeal to conditions for the possibility of the pursuit of truth, or on pursuing the truth efficiently.

To underscore the ecumenical spirit of our thesis, consider three more examples of controversial theses that Truth-Directedness is compatible with, but distinct from. First, some philosophers are attracted to the idea that belief "aims at the truth" in some interesting sense. ${ }^{14}$ If combined with the thought that the epistemic norms are the constitutive norms of belief, this sort of approach could be developed into an appropriately truth-directed grounding account of the sources of basic epistemic justification. Second, Selim Berker (2013) argues against a view that he calls "epistemic teleology", which combines TruthDirectedness with the assumption that "directedness" should be construed as a promotion relation, and that the goods to be promoted can be aggregated. The thesis defended here is compatible with either accepting or rejecting these further assumptions.

Third, critics of pragmatic encroachment in epistemology sometimes appeal to claims similar to Truth-Directedness. However, the Truth-Directedness of epistemic justification is compatible with most recent defenses of pragmatic encroachment concerning knowledge (e.g. Hawthorne 2004, Stanley 2005, Fantl and McGrath 2010). Roughly, this is the view that whether a given body of evidence suffices to put a subject in a position to know that $\mathrm{P}$ can depend upon the practical risks involved in the agent's relying upon $\mathrm{P}$ in their practical deliberation. Both the standard formulations of this view, and the standard

\footnotetext{
${ }^{13}$ This simple proposal is intended only as an illustration. Perhaps, as Schechter and Enoch (2006, 705) worry, direct appeal to truth-preservation in this example is objectionably reliabilist. That would not count against Truth-Directedness, because there are multiple ways of making good on Truth-Directedness that are not reliabilist. See $\S 3$ for discussion.

${ }^{14}$ For some of the different takes on how to best understand the idea that "belief aims at the truth" see Velleman 2000, Wedgwood 2002, Shah 2003, and Gibbard 2008.
} 
motivations for adopting it hold fixed facts about epistemic justification. ${ }^{15}$ The central role of practical stakes, on these views, is to adjust the threshold of justification required for knowledge. ${ }^{16}$

As the broad compatibility just sketched makes clear, Truth-Directedness is a highly schematic theory in the foundations of epistemology. This indeterminacy might seem objectionable, but it is not. Rather, it is dialectically crucial. Disputes between the sorts of approaches mentioned above are central to contemporary epistemology. TruthDirectedness is intended to be powerfully ecumenical, in virtue of being compatible with all of these approaches. Indeed, we take commitment to something like Truth-Directedness to be close to common ground in epistemology. Thus, when epistemologists seek to explain the foundations of epistemic justification, they predictably advert to similar theses. Here is one representative example, from Paul Moser: ${ }^{17}$

Epistemic justification is essentially related to the so-called cognitive goal of truth, insofar as an individual belief is epistemically justified only if it is appropriately directed toward the goal of truth. (Moser 1985, 4)

The presumption of something like Truth-Directedness is so entrenched that it can be hard for even a radical to defeat: Stephen Stich reports that, when philosophers first confronted his heterodox argument that truth should not be the aim of our epistemic practices, many of them simply "assume[d] I must be joking, or propounding silly skeptical puzzles" (1990, $101) .^{18}$

\footnotetext{
${ }^{15}$ For example, all of the philosophers cited above appeal to (roughly) the claim that if one knows that $\mathrm{P}$, one can rationally rely on $\mathrm{P}$ in one's practical reasoning. Mark Schroeder (2012) offers an additional rationale for pragmatic encroachment, arguing that even if only evidence constitutes reason to believe, pragmatic considerations can enter into an account of knowledge by providing reasons to suspend judgment. Neither of these rationales can easily be adapted to an account of the sources of basic epistemic justification.

${ }^{16}$ Note, however, that if one combined pragmatic encroachment with the view that the evidence that constitutes a subject's justification for belief just is that subject's knowledge, pragmatic encroachment on knowledge would also infect prima facie justification. Such a combination is not compatible with Truth-Directedness.

${ }^{17}$ See Berker 2013, $\S 3$ for dozens of endorsements by epistemologists of similar (often stronger) theses about the relationship between epistemic justification and truth.

${ }^{18}$ We take Stich's radical challenge to be highly important. We set it aside here, however, because addressing it would require an entirely distinct sort of argument.
} 
There is a powerful explanation of the strength and breadth of endorsement of theses similar to Truth-Directedness. As we have noted, epistemic justification appears both to be substantively normative and (as Hallie shows) very different from ethical justification. Truth-Directedness promises to explain both of these features. On the one hand, the link to truth is distinctive: for example, there does not appear to be a parallel constraint on our ethical norms. ${ }^{19}$ On the other hand, the substantiveness of epistemic normativity can potentially be explained in part by appeal to the intrinsic or instrumental significance of true belief. ${ }^{20}$

Truth-Directedness also helps to address an important challenge that Enoch poses to those philosophers (such as ourselves) who want to reject his account of epistemic justification, but who also want to preserve the role of explanatory indispensability in epistemic justification. The challenge is to identify a principled distinction between those kinds of indispensability that can justify belief, and those that do not $(2011 \mathrm{~b}, 67)$. TruthDirectedness provides the tools needed to accomplish this task.

To repeat, Truth-Directedness is a constraint on candidate vindicating theories, and not a vindicating theory itself. It is thus compatible with many different ways of seeking to vindicate the sources of basic epistemic justification (for example). However, we know what attempts to vindicate inference to the best explanation $(I B E)$ within a truth-directed framework would look like. This is because the overwhelming majority of the literature on the vindication of IBE presupposes something like Truth-Directedness. For example, Peter Lipton (2004, Ch. 11) and Igor Douven (2011 §3) assume without comment that a "justification" of IBE (i.e.: roughly, a vindication) will show that IBE is "truth-tropic" or reliable. And the discussion above suggests alternative accounts that appeal to epistemic responsibility or virtue, or to transcendental conditions on the pursuit of truth. Fully developing any such theory would be no small task. But that is not our goal. Our aim here is to explain, how, with Truth-Directedness in hand, one can have confidence that

\footnotetext{
${ }^{19}$ Compare Alston 2005: Alston abandons the idea that there is a single category of epistemic justification. Still, he is able to characterize various features as epistemic desiderata in large part because all of them are in some way or another truth-directed.

${ }^{20}$ One example: the central "problem of normativity" in contemporary knowledge-centric epistemology is arguably to explain why knowledge is relevantly better than mere true belief, given that truth is the fundamental normative currency of epistemology. Cf. e.g. Sosa 2007, Lecture 4.
} 
explanatory indispensability could be vindicated as a source of basic epistemic justification, even if deliberative indispensability is not.

In this subsection, we have introduced Truth-Directedness, and argued that it is explanatorily powerful in a way that has earned it remarkable allegiance in contemporary epistemology. We now put Truth-Directedness to work in building our case against Pragmatic. Our case begins, in the next subsection, by sketching three counterexamples to Pragmatic.

\subsection{Three cases against Pragmatic}

Enoch's accounts of intrinsic and instrumental indispensability are intended to be capacityrelative (note Enoch's judicious use of "to us" language at 2011, 70-71). This means that, on Enoch's account, the sources of epistemic justification that are basic for us may not be basic for a creature with quite different capacities. For example, sense perception would not be instrumentally indispensable to a god-like being that had direct intuitive epistemic access to the complete nature of reality. And so, on Enoch's account, it would not count as a source of basic epistemic justification for such a being. We think that this assumption of capacityrelativity is essential to the plausibility of Enoch's account: why would instrumental indispensability for some other sort of creature determine what we had reason to believe? However, this feature of the account also makes it vulnerable to our first two counterexamples.

\section{Case One: Sparky and Sally}

Suppose that ingenious artificial intelligence researchers have designed an AI ("Sparky") capable of having full-fledged beliefs about the world. Sparky is epistemically similar to an ordinary person ("Sally") in the following respects: Sparky's capacities (and limitations) with respect to memory and to reasoning processes that concludes in belief are identical to Sally's. Further, across Sally's whole life, Sparky has been rigged up to Sally so that Sparky receives exactly the sensory evidence that Sally does. We stipulate just one 
crucial difference between Sally and Sparky. Perhaps Sparky does some things that count as actions, but unlike Sally, Sparky is simply incapable of deliberating about what to do. ${ }^{21}$

Plausibly, at any given time in Sally's adult life, Sally and Sparky share (very nearly) the same total evidence. After all, they have been exposed to very nearly the same sensory evidence. Their memories are qualitatively nearly identical. Their senses are similarly connected to the very same environment. And they have identical capacities and dispositions to form beliefs on the basis of these inputs.

Suppose further that, in light of their parallel capacities and circumstances, Sally and Sparky engage in ethical reasoning in exactly the same ways at exactly the same times: when Sally trusts some moral testimony, so does Sparky; when Sally finds a thought experiment or principle intuitively compelling, so does Sparky. So Sally and Sparky in fact accept all the same ethical propositions, on the same bases. For Sparky, of course, this reasoning has purely theoretical significance, while Sally often acts on the basis of her ethical conclusions.

This description makes it highly intuitively plausible that at any given time, Sally and Sparky are almost always justified to the same extent in believing the very same propositions. ${ }^{22}$ There is one plausible exception: Sally will have plenty of introspective and memory evidence as of deliberating, which Sparky will lack, so she will have many justified beliefs like Sally was choosing between soup and salad at dinner that Sparky may lack. However, it is hard to imagine this affecting how justified each of them is in accepting an ethical or metaethical proposition. On Enoch's account, however, Sally has a rationally required project (practical deliberation) that Sparky lacks. So, Enoch's account suggests that Sally

${ }^{21}$ One might question whether Sparky is genuinely possible. For example, on a standard functionalist account of psychology, a belief is a state that, inter alia, interacts with desires in certain ways. Functionalism would thus take a dim view of Sparky imagined as a "pure thinker" with beliefs but no desires. However, we insist only that Sparky lack only the capacity for deliberation (as Enoch conceives of that capacity; 2011b, 70-73). This is compatible with Sparky possessing desires, because functionalists are paradigmatically happy to ascribe beliefs and desires to animals that lack sophisticated deliberative capacities of the sort Enoch's argument appeals to. This point, combined with the intuitive conceivability of a creature like Sparky, constitute a strong case for Sparky's genuine possibility.

${ }^{22} \mathrm{Or}$, if epistemic permissivism is true, the same range of attitudes is permissible for each of them to take towards a given proposition. On epistemic permissivism, see White 2005. 
has some defeasible epistemic justification for believing that there are ethical facts that Sparky lacks. This, we submit, is very odd.

The force of the oddity can be illustrated by comparing our case to a more familiar "new evil demon" case, inspired by the initial discussion in Stewart Cohen and Keith Lehrer's (1983). This case compares two agents who are "perspectival" duplicates: they have identical beliefs, apparent memories, and confront identical perceptual appearances. The difference between these agents is that the perceptual appearances which in the one agent arise from reliable sense perception are in the other the result of demonic illusion. There is strong intuitive pull to think that agents like these are also intuitively justificational duplicates, and that this constitutes a serious problem for reliabilist accounts of justification. While the case is powerful, justification "externalists" can potentially bite the bullet here, in part by appealing to their central arguments that causal or modal connection to the world are justification-conferring. Our case is intended to be more dialectically powerful, by holding parallel all of the features - both "internal" and "external" - that contemporary epistemologists typically find relevant to epistemic justification. Indeed, the case is intended to isolate only the distinctive alleged source of epistemic justification entailed by Enoch's account.

However, this is exactly what makes Enoch's account so implausible. Sally is supposed to have more justification for believing that there are ethical facts than Sparky. But the only difference between Sparky and Sally is that Sally engages in a valuable activity that Sparky does not, and that activity would not be valuable if there were no ethical facts. It is very hard to see how this difference could make Sally more justified than Sparky. Thus, we claim, the case of Sparky and Sally is a counter-example to Enoch's theory.

Case Two: Declan

Next consider Declan, an ordinary agent who has never thought about metaethics. He has no beliefs about whether there are ethical facts, and if he thought about it, he would 
simply suspend judgment on the matter. ${ }^{23}$ On Enoch's account, were Declan to consider whether there are ethical facts, he would have some justification for believing that there are, on the basis of their indispensability for his deliberative life. Now imagine that an evil demon temporarily eliminates Declan's capacity to deliberate (without his noticing), and does nothing else. On a straightforward reading of Enoch, Declan thereby becomes less justified in believing in ethical facts. But it is very odd to think that such a demon can alter Declan's epistemic situation simply by switching on and off his non-epistemic capacities. By contrast, there is nothing odd about a demon altering what Declan is justified in believing by altering his access to uncontroversial sources of basic epistemic justification. For example, if the demon eliminates Declan's ability to remember that $\mathrm{P}$, this can seriously impinge upon Declan's justification for believing that $\mathrm{P}$.

Case Three: Marjorie

Marjorie has strong empirical evidence that her deliberation is not causally efficacious. This evidence suggests that she is in a science fiction dystopia, where, whenever she deliberates and decides what to do, certain diabolical scientists intervene, and prevent her intention from guiding her action. In fact, however, Marjorie is in a different science fiction dystopia, where the scientists interfere with her perceptual faculties, memories, and sense of self-control, but leave the connection between her decisions and actions untouched. Now consider the following de se belief: the results of my deliberation have some chance of being causally efficacious. It may be possible to deliberate absent this belief. ${ }^{24}$ However this belief is plausibly instrumentally indispensable in Enoch's sense: the central reasons that one has to deliberate would surely be radically undermined by the inefficacy of one's deliberation. This means that, on Enoch's account, Marjorie has indispensabilitybased basic justification for believing that her deliberations are causally efficacious.

\footnotetext{
${ }^{23}$ Does this imply that Declan is irrational, given Enoch's account? No. For deliberative indispensability provides only defeasible justification, and Declan could be in the presence of relevant defeaters.

${ }^{24}$ Bratman 1987, 37-8 has offered counterexamples against the idea that A-ing intentionally requires belief that one can A. For example, someone recovering from paralysis might intentionally flex her hand behind her back, despite not knowing whether she is doing so, or indeed whether she is able to do so. If one is compelled by some cases, one should also allow that such an agent could deliberate about whether to flex her hand behind her back.
} 
This case exploits the fact that if deliberative indispensability provides basic justification for believing that there are ethical facts, it will also provide basic justification for believing ordinary contingent propositions. This is embarrassing for Enoch because beliefs like the one mentioned - which concern the distribution of contingent causal connections - seem paradigmatically amenable only to justification on the basis of empirical evidence. ${ }^{25}$ Deliberative indispensability, however, appears to be an a priori mode of justification. On Enoch's account, Marjorie's empirical evidence has to compete with and outweigh her alleged deliberatively-based a priori evidence that she can affect the world via her deliberations. This, we submit, is implausible.

\subsection{Why Enoch's vindicating account fails}

This discussion puts us in a position to spell out our central objection to Enoch: Pragmatic violates the constraint on vindicating accounts of the sources of basic epistemic justification constituted by Truth-Directedness. This is because the fact that the belief that $\mathrm{P}$ is indispensable to our deliberative projects bears no positive relationship to the truth of P. Indeed, Enoch never claims that it does. Rather, he appeals to a different normative significance for this belief: that it is indispensable to a rationally non-optional project. But, as we have emphasized in $\S 2.1$, it is not enough for a vindicating account of the sources of basic epistemic justification to be normatively significant; such an account must also capture what is distinctive of epistemic justification, which (we have argued) requires compatibility with Truth-Directedness.

The fact that Pragmatic violates the Truth-Directedness constraint explains the force of the three counterexamples just offered. Consider them in turn. The difference between Sparky and Sally is that Sally has an indispensable project that Sparky lacks. That may give Sally all sorts of ethical reasons. But it is instructive to compare Sally to Hallie: the demon's threat is unconnected to the truth of Hallie's belief in his golden voice, and that explains why the demon's threat does not justify. The instrumental indispensability of Sally's belief in ethical facts appears unrelated to the truth of Sally's belief in just the same way. In the second case: turning on and off Declan's capacity to deliberate about what to

\footnotetext{
${ }^{25}$ We thank David Enoch helping us to clarify the force of this case.
} 
do does not affect what he is justified in believing, because this capacity does not add any connection (causal, modal, perspectivally relative, or otherwise) to the facts that was lacking in its absence. Finally, in the third case: we are confident that sense perception is the specific mode of connection to the world appropriate to justify belief in contingent facts about causal connections. The deliberative indispensability of Marjorie's believing that her deliberation can be causally efficacious thus appears justificationally irrelevant. We take these highly plausible theoretical explanations of the force of the intuitive cases to substantially augment the force of the cases themselves.

Further, in virtue of violating Truth-Directedness, Pragmatic offers inferior explanations of why some candidate sources of evidence are not basic justifiers. ${ }^{26}$ For example, why doesn't reading tea leaves provide basic justification for beliefs about your fate? Here are two (schematic) candidate explanations: (1) the beliefs that result from standard methods of tea-leaf reading bear no positive relation to facts about your fate; (2) reliance on tea-leaf reading is not instrumentally indispensable to a rationally indispensable project. Both (1) and (2) seem true. (Although one can easily imagine a benighted soul whose fragile grasp on the shreds of meaning in his life required trust in the tea leaves). But (1) is intuitively a much better answer to our explanatory question than (2).

For another example, consider a case of active controversy in foundationalist circles: whether testimony is a source of basic epistemic justification. Pragmatic suggests that this controversy could be resolved in large part by determining whether reliance on testimony is instrumentally indispensable to an intrinsically indispensable project. It plausibly is: living well with others is plausibly an intrinsically indispensable project for creatures like us, and defeasibly trusting their testimony seems instrumentally indispensable to that project. But this seems like the wrong sort of consideration to settle the outstanding debate about the foundational status of testimony.

Finally, note that it may be possible to come up with piecemeal replies to some of our counterexamples. However, we think this would be a losing strategy for the defender of Pragmatic. With Truth-Directedness in hand, we have a recipe for generating counterexamples to Pragmatic: construct cases where Pragmatic endorses as epistemically

\footnotetext{
${ }^{26}$ We are indebted to Brad Cokelet for this point.
} 
basic methods that lack plausible connection to the truth. ${ }^{27}$ Such counterexamples will be legion.

One might object on Enoch's behalf here that deliberation is truth-directed. In particular, one might object that often, when we engage in deliberation, we deploy our rational capacities to answer the (purportedly) factual question: what ought I to do? One might then take a page from another of Enoch's arguments (2011, Ch. 7), and suggest that we have reason to believe that our practical deliberation is in fact acceptably reliable, because evolution has fitted us to track something close to the ethical facts.

While this objection is initially seductive, it ultimately either misunderstands our objection, Enoch's view, or both. It is crucial to our account that a vindicating account does not merely point to a belief-forming method that in fact bears some positive connection to the truth (recall that our example of the divine command theory of epistemic justification in $\S 2.1$ satisfied this criterion). Rather, on our theory, a legitimate vindicating account must appeal to this positive connection to explain why something is a source of basic epistemic justification. And, as we have emphasized, Pragmatic simply does not do that. Because our argument here is directed against this explanatory theory, the question of whether the deliberative methods that theory endorses also happen to be in some sense positively connected to the truth is simply irrelevant.

We conclude that Pragmatic should be rejected. We have argued that it faces serious intuitive counterexamples. Further, this vulnerability to counterexample is wellexplained by the fact that Pragmatic violates a powerful constraint on vindicating accounts of the sources of basic epistemic justification, namely: Truth-Directedness.

The failure of Pragmatic does not by itself show that no defensible vindicating account can be given that would underwrite Indispensabilism. Nor does it establish our more ambitious thesis: that Indispensabilism must be rejected. However, our argument against Pragmatic does provide the materials needed in order to extend our argument to both of these stronger conclusions. We turn to that task in the next section.

\footnotetext{
${ }^{27}$ For another example that fits this recipe, see Cuneo's case for the instrumental indispensability of having a positive self-image $(2012,1064)$.
} 


\section{Alternative vindicating accounts and Indispensabilism}

As we saw in Section 1, there are good reasons to seek a vindication of the sources of basic epistemic justification. To repeat, a vindication of those basic sources is, roughly, a non-epistemic explanation of why the sources are what they are, which upholds (rather than debunks or reforms) our intuitive conception of the nature and importance of those sources. In the previous section, we argued that Pragmatic - Enoch's proposed vindicating account - should be rejected. This is bad news for Enoch. However, it is natural to wonder whether this failure stems from features idiosyncratic to Enoch's particular vindicating account, or whether it generalizes to other attempts to defend Indispensabilism by appeal to a vindicating account of the sources of basic epistemic justification.

In this section, we argue that there are strong reasons to think that the case will generalize to other attempts to vindicate Indispensabilism. The core reason is that deliberative indispensability appears unconnected to the truth. This means that those seeking to vindicate Indispensabilism face a dilemma. On the one hand, you can develop an account that aims to vindicate deliberative indispensability as a basic source of justification. But those accounts will - like Pragmatic - be inconsistent with Truth-Directedness, and thus, we claim, fail to provide an adequate account of epistemic justification. On the other hand, you can aim to provide a vindicating account of the sources of basic epistemic justification that is compatible with Truth-Directedness. Such accounts have some chance of vindicating norms of epistemic justification. But such accounts will not vindicate deliberative indispensability as a basic source. If sound, the dilemma provides good reason to think that Indispensabilism is false.

To begin, consider an example of the second horn of the dilemma. Alvin Goldman (2008) has recently suggested a view that treats reliabilism as (in our terms) a vindicating account of the sources of basic epistemic justification. For example, this account suggests that sense perception is epistemically basic because in a relevant range of cases, the processes that link the world to perceptual states and thence to correlated belief are on the whole marvelously reliable. Such a reliabilist vindicating account of the foundations of epistemic justification is evidently compatible with Truth-Directedness. Indeed, reliabilism is one natural framework for spelling out a substantive justification-truth link. But this vindicating 
account is also hostile to Indispensabilism. ${ }^{28}$ This example will generalize: similar considerations apply to possible vindicating accounts that emphasized alternative modal properties such as sensitivity or the recently fashionable safety, rather than process reliability (Cf. Nozick 1981, Sosa 1999, Roush 2007).

The force of the tension may appear less clear as we move away from modal approaches to satisfying Truth-Directedness. However, consider one of the most influential alternatives to such conceptions, which we will call "responsibilism" about epistemic norms. On this way of thinking about epistemology, norms for epistemic justification are, or are grounded in, (some of the) norms that govern what is required to be a responsible epistemic agent (cf. Chisholm 1977, Bonjour 1985, Greco 1990). On one variant, for a belief to be justified is just for it to have been formed by an epistemically responsible process. For example, on this sort of account, if I believe that $\mathrm{P}$ in virtue of carefully acquiring and assessing the evidence, which I reasonably find to strongly support P, I would be justified in believing $\mathrm{P}$, even if this process is in fact unreliable. ${ }^{29}$ Conversely, if I form my belief that $\mathrm{P}$ irresponsibly - e.g. on a whimsical hunch - I would not be justified, even if my whimsical hunches are in fact very reliable. ${ }^{30}$

The central question for this sort of approach is how to characterize an epistemically responsible process. It is no accident that the responsibilists in epistemology cited above all advert to truth in explaining what epistemic responsibility amounts to. Think again about Hallie: her forming the belief that the demon can sing like Ray Charles would be highly ethically responsible, but a clear violation of her "epistemic duties", if such things exist. And the lack of (first-personally mediated) connection to the truth appears to be an excellent explanation of the latter fact. With this contrast in hand, it becomes very unclear how Indispensabilism could be vindicated as compatible with our fundamental epistemic duties.

\footnotetext{
${ }^{28}$ One could of course here try to present an ambitious argument that deliberative indispensability is a reliable belief-forming method. We think that the prospects for such an argument are not good, and thus leave this possibility to the side for now, in order to streamline our main discussion.

${ }^{29}$ Compare again the "new evil demon"-style cases.

${ }^{30}$ Compare Bonjour's classic case of Norman the clairvoyant 1985, $41 \mathrm{ff}$.
} 
Similar points apply to virtue-epistemic approaches to vindicating the sources of basic epistemic justification. ${ }^{31}$ On a simple version of this account, for a belief to be epistemically justified to some degree is for its possession to manifest epistemic virtue or competence. One could propose analogously that to be a source of basic epistemic justification would be to be a source that the epistemically virtuous would treat as basic. The crucial question facing such an account is to explain what makes something an epistemic virtue. And here the options largely duplicate the preceding discussion. Thus, some philosophers suggest that a trait is an epistemic virtue just in case it plays an appropriate role in securing reliability or other modal relations to the facts (Sosa 2007, Greco 2010). Others suggest that epistemic virtues are to be understood in terms of responsible epistemic agency (Montmarquet 1993). And some important discussions require that epistemic virtues require both responsible aiming at truth, and a reasonable degree of reliability in this endeavor (Zagzebski 1996).

The best hope here to vindicate Indispensabilism would be to endorse a view of epistemic virtue that appeals to whether traits contribute to our overall flourishing. With such a view in hand, the virtue epistemologist could argue that deliberation is an ineliminable element of a flourishing life. Unfortunately, just as Truth-Directedness predicts, such a view will struggle with counterintuitive implications, because epistemic excellence appears compatible with overall vice. Indeed, one can sometimes come by lots of justified beliefs by engaging in intuitively ethically vicious behavior: the callous spy or torturer might use ethically terrible methods to attain epistemic goals. ${ }^{32}$

These brief remarks demonstrate the challenges of attempting a defense of Indispensabilism via the attempt to provide a vindication of the sources of basic epistemic justification. The pattern suggested by these cases makes it plausible that any vindicating account for the sources of basic epistemic justification will either fail to respect the Truth-

\footnotetext{
${ }^{31}$ Like virtue ethics, virtue epistemology is a diverse philosophical movement. Here we explore only one, relatively conservative strand, which preserves a focus on epistemic justification.

${ }^{32}$ Some moral vices may typically include or entail epistemic vices: for example, the sexist typically tends to be blind to certain features of his social environment (cf. Jones 1999), and may tend to illegitimately discount the testimony, reasoning, or novel ideas of his (or her) female peers. The truth-directed virtue epistemologist can treat such vices as epistemically relevant without collapsing epistemic and ethical virtue.
} 
Directedness constraint (and thus, we claim, fail to secure a link to genuine epistemic justification), or fail to support Indispensabilism.

When foundationalists draw up intuitively-motivated lists of the sources of basic epistemic justification, deliberative indispensability almost never gets on the list, alongside reliance on sense perception, memory, IBE, etc. So if deliberative indispensability is going to get on to the list, it needs to do so on theoretical grounds. However, if TruthDirectedness is a central intuitive commitment concerning epistemic justification, any theoretical attempt to vindicate Indispensabilism will need to involve quite radical reform of our understanding of epistemology. For example, one could reject Truth-Directedness as part of a broader meta-philosophical pragmatism. We think that our case for TruthDirectedness tells against such views. However, the dialectic here is notoriously murky, with very little that can be assumed as non-question-begging common ground. We are thus quite satisfied to say: Indispensabilism must be rejected, modulo radical forms of metaphilosophical pragmatism.

\section{Abandoning Indispensabilism.}

In this section, we want to briefly discuss three distinctive replies to our argument. These replies each target a central assumption of our argument: that deliberative indispensability arguments must focus on ethical deliberation; that deliberation does not ground the ethical facts; and that indispensability arguments must deliver epistemic normativity; and that the apparent underlying contrast between epistemic and practical normativity is genuine. Exploring these replies helpfully illuminates the range of assumptions within which our argument operates. These replies are also instructive because each reply abandons Indispensabilism in some way, in order to defend a related thesis.

First, one might hope that the metaethical payoff of Enoch's project could be preserved, and our objection avoided, by the following variant on his argument. Begin by claiming that indispensability to the epistemic (or doxastic, or explanatory) project confers basic epistemic justification. (Notice that this proposal does not violate TruthDirectedness.) Then adapt Enoch's case for the deliberative indispensability of belief in Robustly Real ethical facts, into a case for the indispensability of belief in Robustly Real epistemic facts for doxastic deliberation. This would permit a Truth-Directedness-respecting 
case for Robust Realism about the epistemic facts. The Robust Realist about ethical facts can now appeal to the epistemic as companion in guilt: once we posit some normative facts (conceived of along the lines of Robust Realism), it might seem a small cost to take on commitment to additional normative facts, such as the ethical facts. ${ }^{33}$

Note that this argument abandons Indispensabilism. It grants Truth-Directedness, and seeks to find a variant of Enoch's argument that is compatible with the central points that we have made in this paper. This argument is thus substantially less theoretically exciting that Enoch's. However, if it succeeded in defending Robust Realism about ethical facts, it would deserve substantial independent attention.

We doubt it succeeds, however, for at least two reasons. First, it will not be trivial to adapt Enoch's argument in the way required: Enoch's case for the deliberative indispensability of the ethical facts appeals heavily to phenomenology, and this phenomenology does not smoothly carry over to epistemic deliberation. (For example, deliberation about what to believe is, famously, transparent: we focus on whether P, not whether we ought to believe that P.) This might pose a barrier to defending the deliberative indispensability of epistemic facts. Second, even if the companion in guilt is established, it is not clear that the additional cost of committing to Robustly Real ethical facts is small. One reason why such ontological commitment appears costly is that we lack an adequate account of how epistemic access to Robustly Real normative facts is possible. If the deliberative indispensability argument succeeded in the case of epistemic facts, we would have the requisite account of epistemic access in that case, but still not in the case of ethical facts.

A second important strategy for replying to our argument appeals to an ambitious form of constructivism about ethical facts. Suppose, for example, that ethical facts are determined by a certain privileged (and indispensable) process of practical deliberation. This could be used to deliver an account of our epistemic justification for belief in ethical facts that is entirely consistent with Truth-Directedness. The basic idea here is that the very process of deliberation that commits us to the existence of ethical facts also functions to

\footnotetext{
${ }^{33}$ See Cuneo 2006, for an extended case that the challenges posed to the ethical view carry over to the epistemic one.
} 
ground the existence of those facts. If this were the explanation for why this commitment constituted a source of basic epistemic justification, it satisfies Truth-Directedness.

This is a familiar attempt to make good on the Tempting Idea we mentioned in the Introduction. The challenges facing this view are equally familiar. Enoch himself has forcefully posed some of these challenges in his (2006 and 2011a). We cannot hope to asses this strategy here, but we do want to emphasize that this kind of constructivism about ethical facts does not underwrite Indispensabilism: the constructivist appeals to a domainspecific claim about the metaphysics of ethics, not a global epistemic thesis about the significance of deliberative indispensability. Perhaps this suggested constructivist view which is only about ethical facts in particular - is all that we should have wanted from the Tempting Idea to start with. If so, this brings out the poor fit between Indispensabilism and the intuitive idea it was supposed to underwrite. ${ }^{34}$

Finally, a third reply to our argument is to give up on the idea that deliberative indispensability gives us distinctively epistemic justification. Developed in this way, the Tempting Idea would be wholly compatible with the naturalistic criterion that we initially posed as its foil. For, on that criterion, we are epistemically justified in believing in ethical facts just in case they (or their reduction base) feature in our best explanations of scientifically respectable phenomena. Despite this compatibility, the third reply also comes at a certain cost. It would be interesting, for example, if we were ethically committed to the existence of Robustly Real ethical facts. But if this provides us with no evidence for their existence, the upshot could be a deep and potentially intractable conflict between the demands of practical and epistemic reason. This is an interesting possibility, but not a particularly attractive one.

\footnotetext{
${ }^{34}$ Notice that some philosophers drawn to the Tempting Idea have appealed to a similar idea with respect to a range of types of facts, such as facts about the nature of action, the self, or desire (e.g. Korsgaard 2009, Schapiro 2009). Suppose that certain beliefs about some such facts were practically indispensable. Indispensabilism would then underwrite an inference from that indispensability to epistemic justification. Attempting to replace Indispensabilism with a "constructivist" rationale, however, requires finding an independent metaphysical argument that shows that the relevant facts are grounded in facts about some practical project (e.g., the project of deliberation). Such grounding claims will not be equally plausible for all types of facts. The crucial point about this alternative to Indispensabilism is that the defensibility of indispensability arguments for epistemically justified belief in a class of facts will stand or fall with the plausibility of a "constructivist" metaphysics for that class of facts.
} 
Summing up, we think that each of these responses that we have considered here faces significant challenges, and we are not hopeful about any of them. Thus, although our main argument in this paper is directed at Indispensabilism, we take our argument to have another upshot as well: it helps clarify the range of ways that one might seek to make good on the Tempting Idea that we started with, and underscores the significant philosophical burdens that one takes on in trying to do so.

\section{Conclusion}

This paper has been dedicated to evaluating the prospects of the following thesis:

Indispensabilism If a belief-forming method is indispensable to the project of practical deliberation, then that method is a source of basic epistemic justification

One striking reason to be drawn to this thesis is that our commitment to the existence of ethical facts can seem to arise from their apparent deliberative indispensability, rather than from any role that they play in explaining scientifically respectable phenomena. A modest methodological conservatism enjoins us to try to uphold this etiology as justificationconferring. This is a scrupulously reasonable project. However, we have argued that it likely cannot be successfully accomplished.

The heart of our argument has been that in order to vindicate the epistemic credentials of Indispensabilism, one would need to show that it is compatible with what is distinctive of epistemic justification. We explored Enoch's sophisticated recent attempt to vindicate Indispensabilism, and argued that it falls well short. Our argument rested heavily on a characterization of (part of what) makes epistemic justification distinctive. According to this thesis, which we dubbed Truth-Directedness, the explanation of what makes something a source of basic epistemic justification must advert to a connection between that source and the truth of the proposition justified. This thesis attempts to bring out a fundamental difference between the norms of epistemic justification and those of practical justification, suggested at the start of the paper by our example of Hallie and the demon. We argued that Enoch's defense of Indispensabilism violated Truth-Directedness. We then argued that Enoch's failure to successfully defend Indispensabilism is no accident: we have reason to be confident that similar challenges will plague other attempts to defend 
Indispensabilism. Finally, we discussed ways of attempting to appeal to deliberative indispensability in metaethics that abandon Indispensabilism.

Both Indispensabilism and Truth-Directedness share a substantive foundationalist assumption about epistemic structure. This is a significant limitation of our argument as developed here, because one can easily imagine theses similar to Indispensabilism that eschew the foundationalist assumption. We conjecture that principles similar to TruthDirectedness could be used to raise very similar problems for these theses. However, we do not have the space to defend this claim here.

We would like to close by briefly underscoring some of the broader metaethical import our argument. First, consider the significance of this conclusion for the assessment of Robust Realism in metaethics. Enoch gives two main positive arguments for his Robust Realism in (Enoch 2011b). In rough terms, the first argument is that we need to endorse Robust Realism in order to make sense of a certain form of objectivity about moral facts that (purportedly) we are all committed to (2011b, ch. 2). The second argument is the argument from deliberative indispensability. Without the support of this second argument, the positive case for Robust Realism then rests solely on the argument from moral objectivity. Although we don't have space to discuss it here, we think that argument is even less promising than this argument from deliberative indispensability. Even if we are incorrect about this, the argument from objectivity is a remarkably slender positive case for an incredibly ambitious metaethical view.

Moreover, the defeat of Enoch's argument from deliberative indispensability doesn't just undercut a positive argument he has for Robust Realism. The argument from deliberative indispensability plays two other major roles in his defense of Robust Realism. First, Enoch uses the argument to defend Robust Realism against a common naturalist objection to non-naturalist metaethical views: given that (according to the relevant kind of non-naturalist) these ethical facts (or their reduction base) are not part of our best explanation of any scientifically respectable phenomena, we lack epistemic justification for believing in them. Second, Enoch also uses the argument to explain how we can have epistemic justification for belief in Robustly Real ethical facts without recourse to anything akin to a special perceptual faculty for learning about these facts - something that many have worried non-naturalists will be forced to posit. Without his argument from 
deliberative indispensability to turn to, Enoch's preferred responses to both of these challenges to metaethical non-naturalism are undercut. We conclude that this leaves the Robust Realist about ethical facts in bad shape.

Our assessment of Indispensabilism in this paper has metaethical significance that extends beyond the assessment of Robust Realism. Many philosophers - including philosophers who advocate metaethical positions quite different from Robust Realism have been attracted to some version of the Tempting Idea that we introduced at the start of this paper. To repeat, this was the idea that the (putative) indispensability of belief in ethical facts for our practical projects - including, for example, the project of deliberating about what to do - can somehow justify our belief in such facts. If our argument in this paper is right, then one of the clearest ways of making good on this idea, namely, Indispensabilism, should be rejected. Moreover, as we discussed in (§4), there are serious worries with some of the other salient ways that one might seek to make good on the Tempting Idea, e.g., by giving up on the idea that the sort of justification involved is genuinely epistemic justification, or by pursuing an ambitious constructivism about ethical facts.

To sum up, then, we have argued for three conclusions concerning the epistemic and metaethical significance of practical indispensability. First, we should reject Enoch's indispensabilist case for Robust Realism about ethical facts. Second, we should reject Indispensabilism in general: deliberative indispensability does not epistemically justify belief. Third, there are good reasons to be skeptical of the metaethical significance of deliberative indispensability, as well as practical indispensability more broadly.

\section{WORKS CITED}

Alston, William. 2005. Beyond Justification: Dimensions of Epistemic Evaluation: Ithaca: Cornell University Press.

Berker, Selim. 2013. Epistemic Teleology and the Separateness of Propositions. Philosophical Review 122 (3):337-393.

BonJour, Laurence. 1985. The Structure of Empirical Knowledge: Harvard University Press.

Boyd, Richard. 1997. How to be a Moral Realist. In Moral Discourse and Practice, edited by S. Darwall, A. Gibbard and P. Railton. New York: Oxford University Press. 
Bratman, Michael. 1987. Intention, Plans, and Practical Reason. Cambridge, Mass.: Harvard University Press.

Broome, John. 1999. Normative requirements. Ratio 12 (4):398-419.

Chisholm, Roderick M. 1977. Theory of Knowledge: Englewood Cliffs, N.J.,Prentice-Hall.

Cuneo, Terence. 2007. The Normative Web: An Argument for Moral Realism: Oxford University Press.

_ 2012. Taking Morality Seriously: A Defense of Robust Realism, by David Enoch. Mind 121 (484):1059-1064.

Douven, Igor. 2011. Abduction In Stanford Encyclopedia of Philosophy, edited by E. N. Zalta. http://plato.stanford.edu/archives/spr2011/entries/abduction

Dworkin, Ronald. 2011. Justice for Hedghogs. Cambridge: Harvard University Press.

Enoch, David. 2006. Agency, Shmagency: Why Normativity Won't Come from What Is Constitutive of Action. Philosophical Review 115 (2):169-198.

. 2007. An Outline of an Argument for Robust Metanormative Realism In Oxford Studies in Metaethics Volume 2, edited by R. Shafer-Landau. Oxford: Oxford University Press.

. 2011a. Can there be a global, interesting, coherent constructivism about practical reason? Philosophical Explorations 12 (3):319-339.

- 2011b. Taking Morality Seriously: A Defense of Robust Realism. Oxford: Oxford University Press.

Enoch, David, and Joshua Schechter. 2008. How are basic belief-forming methods justified? Philosophy and Phenomenological Research 76 (3):547-579.

Gibbard, Allan. 2008. Rational Credence and the Value of Truth. In Oxford Studies in Epistemology, Volume 2, edited by T. Gendler and J. Hawthorne. Oxford: Oxford University Press.

Goldman, Alvin. 2008. Immediate Justification and Process Reliabilism. In Epistemology: New Essays, edited by Q. Smith: Oxford University Press.

Greco, John. 1990. Internalism and epistemically responsible belief. Synthese 85 (2):245 277. . 2010. Achieving Knowledge: A Virtue-Theoretic Account of Epistemic Normativity: Cambridge University Press.

Harman, Gilbert. 1977. The Nature of Morality. Oxford: Oxford University Press.

Husi, Stan. 2013. Why Reasons Skepticism is Not Self-Defeating. European Journal of Philosophy 21 (3):424-449.

Jones, Karen. 1999. Second-hand moral knowledge. Journal of Philosophy 96 (2):55-78.

Kolodny, Niko. 2005. Why be rational? Mind 114 (455):509-563.

Korsgaard, Christine M.1996. The sources of normativity. New York: Cambridge University Press.

2009. Self-Constitution: Agency, Identity, and Integrity. Oxford: Oxford University Press.

Lehrer, Keith, and Stewart Cohen. 1983. Justification, truth, and coherence. Synthese 55 (2):191 - 207.

McPherson, Tristram. 2011. Against quietist normative realism. Philosophical Studies 154 (2):223-240.

Montmarquet, James. 1993. Epistemic Virtue and Doxastic Responsibility. Vol. 29: Rowman \& Littlefield. 
Moser, Paul. 1985. Empirical Justification. London: Springer.

Nozick, Robert. 1981. Philosophical Explanations: Harvard University Press.

Roush, Sherrilyn. 2007. Tracking Truth: Knowledge, Evidence, and Science: Oxford University Press.

Scanlon, T. M. 2014.Being Realistic About Reasons. Oxford: Oxford University Press.

Schapiro, Tamar. 2009. The nature of inclination. Ethics 119 (2):229-256.

Schechter, Joshua, and David Enoch. 2006. Meaning and Justification: The Case of Modus Ponens. Noûs 40 (4):687 - 715.

Schroeder, Mark. 2012. Stakes, Withholding, and Pragmatic Encroachment on Knowledge. Philosophical Studies 160 (2):265-285.

Shah, Nishi. 2008. How Action Governs Intention. Philosophers' Imprint 8 (5):1-19.

Sosa, Ernest. 1999. How to defeat opposition to Moore. Philosophical Perspectives 13 (s13):137-49.

. 2007. A Virtue Epistemology: Apt Belief and Reflective Knowledge, Volume I. Oxford: Oxford University Press.

Stitch, Stephen. 1990. The Fragmentation of Reason. Cambridge, MA: MIT Press.

Trogdon, Kelly. 2013. An Introduction to Grounding. In Varieties of Dependence, edited by M. Hoeltje, B. Schnieder and A. Steinberg. 97-122. Munich: Philosophia Verlag.

Velleman, J. David. 2000. The Aim of Belief. In The Possibility of Practical Reason. Oxford: Oxford University Press.

Wedgwood, Ralph. 2002. The Aim of Belief. Philosophical Perspectives 16:267-297.

White, Roger. 2005. Epistemic permissiveness. Philosophical Perspectives 19 (1):445-459.

Williams, Bernard. 1973. Deciding to Believe. In Problems of the Self: Cambridge University Press.

Zagzebski, Linda. 1996. Virtues of the Mind: An Inquiry Into the Nature of Virtue and the Ethical Foundations of Knowledge: Cambridge University Press. 